
May 1938

\title{
MINIMUM PERCEPTIBLE COLORIMETRIC PURITY AS A FUNCTION OF DOMINANT WAVE LENGTH
}

\author{
By Irwin G. Priest and Ferdinand G. Brickwedde *
}

[Editorial Note.-In February 1926, Priest and Brickwedde presented the results of their study of colorimetric purity before the Optical Society of America and an abstract, carrying the title given above, appeared in the J. Opt. Soc. Am. and Rev. Sci. Instr. 13, 306 (1926). The work had not been prepared for publication at the time of Mr. Priest's death, and Dr. Brickwedde is now working in another field. Therefore, at the suggestion of the Director of the National Bureau of Standards, the writer has undertaken the preparation of this article.Deane B. Judd.]

\section{ABSTRACT}

A $4^{\circ}$ square, two-part photometric field, symmetrical about a vertical division and viewed through a pupil $3 \mathrm{~mm}$ in diameter, is illuminated in both parts by artificial sunlight at a constant brightness of about 3 or $4 \mathrm{~mL}$ (retinal illumination, 70 to 90 photons) with a surrounding field of about $0.5 \mathrm{~mL}$. Homogeneous light is added to one half, and sunlight simultaneously subtracted so that the field remains matched in brightness. Two adjustments of the mixture are made: (1) The least purity perceptible with certainty $\left(p_{\max }\right)$, and (2) the greatest imperceptible purity $\left(p_{\min }\right)$. The purity of these mixtures is then measured, increased accuracy being obtained by measuring a known large multiple of the homogeneous brightness. Values of $p_{\max }$ and $p_{\min }$ have been obtained as a function of the wave length of the homogeneous component; these values are reported in detail, and some diseussion of their interpretation is given.

\section{CONTENTS}

I. Introduction

II. Procedure

1. Adjustment of the mixture

2. Photometric measurement of the components........ 674

3. Precautions and auxiliary studies.

III. Results______ 676

IV. Discussion

1. Comparison with other work

2. Interpretation

\section{INTRODUCTION}

This work is undertaken as a part of a program of research on determination and correlation of the characteristics of vision outlined by Priest ${ }^{1}$ in 1921 when he listed as one of the functions to be determined, "Saturation sensibility-the least change in purity perceptible as a change in saturation." This work deals with saturation sensibility near zero purity. ${ }^{2}$ It is therefore of particular interest in the colorimetry of illuminants closely resembling sunlight in color

*Research Associate at the National Bureau of Standards, representing the Munsell Research Laboratory, July 1925 to June 1926.

1 Irwin G. Priest, The spectral distribution of energy required to evoke the gray sensation, BS Sci. Pap. 17, 231 (1922) S417 (see Appendix, p. 260).

2 For a definition of colorimetric purity, see Irwin G. Priest, Apparatus for the determination of colc. in terms of dominant wave length, purity, and brightness, J. Opt. Soc. Am. and Rev. Sci. Instr. 8, 173 (1924); Irwin G. Priest, The computation of colorimetric purity, J. Opt. Soc. Am. and Rev. Sci. Instr. 9, 503 (1924). 
and in the colorimetry of nearly achromatic surface colors viewed under such illuminants; it bears importantly upon the question of tolerances in the specification of such colors and upon the determination of nearest color temperatures ${ }^{3}$ by means of which such illuminants are customarily specified.

\section{PROCEDURE}

\section{ADJUSTMENT OF THE MIXTURE}

A $4^{\circ}$ square, two-part photometric field, symmetrical about a vertical division and viewed through a pupil $3 \mathrm{~mm}$ in diameter, was illuminated in both parts by Abbot-Priest sunlight ${ }^{4}$ at a constant brightness of about 3 or $4 \mathrm{~mL}$ (retinal illumination, 70 to 90 photons) with a surrounding field of about $0.5 \mathrm{~mL} .^{5}$ Homogeneous light was added to the right half of the field and sunlight simultaneously subtracted so that the right half of the field remained matched in brightness with the unchanged left half. Two adjustments of the mixture in the right half-field were made. First the proportion $(p)$ of homogeneous light in the mixture was increased until the observer perceived a definite chromaticity difference between the sunlight in the left half and the mixture in the right; this is called a setting of the least purity perceptible with certainty $\left(p_{\max }\right)$. The observer then decreased the proportion of homogeneous light in the mixture until the chromaticity difference just disappeared. This second adjustment is called the greatest imperceptible purity $\left(p_{\mathrm{min}}\right)$. The average between a setting of least perceptible difference and a setting of greatest imperceptible difference is thought to be a more reliable indication of sensibility than either one taken alone; it has sometimes been called the "doubtful difference." 6 Accordingly, this average has also been computed and is referred to as $\left(p_{\text {mean }}\right)$.

\section{PHOTOMETRIC MEASUREMENT OF THE COMPONENTS}

After each adjustment (either of least perceptible or greatest imperceptible difference) the observer made a photometric measurement of the components of the mixture from which the purity $\left(p_{\max }\right.$ or $\left.p_{\min }\right)$ may be computed. One of two photometric methods was used.

In the equality-of-brightness method, the nonselective filter in the homogeneous beam was removed. Since this filter was usually either of 5- or 10-percent transmission, the homogeneous component by this operation was increased either twentyfold or tenfold. Then the observer decreased the sunlight component of the right half of the field until the brightness was again judged equal to that of the left half which remained unaltered throughout. The reduction in sunlight component was accomplished by increasing the distance of the lamp from a diffusing screen; it may therefore be expressed as a simple function of this distance (essentially the inverse-square law). This reduction is equal to a known multiple (usually about 19 or 9 ) of the homogeneous brightness, and thus permits the ratio of homogeneous

\footnotetext{
${ }^{3}$ R. Davis, $A$ correlated color temperature for illuminants, BS J. Research 7, 659 (1931) RP365.

4 Irwin G. Priest, $A$ precision method for producing artificial daylight, Phys. Rev. [2] 11, 502 (1918); J. Opt. Soc. Am. and Rev. Sci. Instr. 12, 479 (1926). D. B. Judd, Reduction of data on mirture of color stimuli, BS J. Research 4, 525 (1930) RP163.

${ }_{5}$ Irwin G. Priest, Apparatus for the determination of color in terms of dominant wavelength, purity, and brightness, J. Opt. Soc. Am. and Rev. Sci. Instr. 8, 173 (1924).

6 D. B. Judd, Sensibility to color-temperature change as a function of temperature, J. Opt. Soc. Am. 23, 7 (1933).
} 
brightness component to brightness of the mixture to be computed. This ratio is the colorimetric purity of the mixture.

The equality-of-brightness method is convenient but it is open to two criticisms: First, the field size ( $4^{\circ}$ square) is larger than that to which the standard luminosity function recommended by the International Commission on Illumination applies, ${ }^{7}$ and second, the observer has to make the photometric match with a considerable chromaticity difference (sometimes amounting to 20 least perceptible differences) between the two halves of the field. Accordingly, for about half of the work, the brightnesses of the components of the mixture were obtained by flicker photometry.

In the flicker method a $2^{\circ}$ diaphragm was substituted for the rectangular 2 by $4^{\circ}$ opening constituting the mixture field. The nonselective filter in the homogeneous beam was removed, and the flicker disk interrupting the homogeneous beam with sunlight of brightness variable by an auxiliary photometer was set into rotation at a suitable speed. Adjustment of the auxiliary photometer for minimum flicker yields a measure of the brightness of this known multiple of the homogeneous component. From this brightness and the known constant brightness of the photometric field the purity of the mixture ( $p_{\max }$ or $\left.p_{\text {min }}\right)$ was computed.

\section{PRECAUTIONS AND AUXILIARY STUDIES}

The wave-length scale was calibrated by reference to the lines of the helium emission spectrum. Stray light in the spectrum was measured and stray-light filters used in the extremes of the spectrum over the whole region within which stray light would introduce appreciable errors. This is particularly important for the short-wave region of the spectrum.

A special check was made (observer IGP) of the slit-width errors. These errors can be shown by computation to be negligible in comparison with the inherent uncertainty of liminal settings even for the rather large slit widths used $(10 \mathrm{~m} \mu)$. The experimental check corroborated the computations.

A special study was made (observer FGB) of the variation of $p_{\max }$ and $p_{\mathrm{m} \text { in }}$ taken on different days over a period of 6 weeks. It was found that there was no regular variation from day to day, but the mean for a given day varied on the average from the mean on another day by more than would be expected from the theory of errors. This is probably to be ascribed to a change in criterion of what constitutes a "just perceptible" and a "just imperceptible" difference; such variations are common, and indeed, characteristic of liminal settings. ${ }^{8}$ The conclusions from this study were used in a special determination of the wave length of the maximum value of $p_{\text {mean }}$ (observer, FGB). This determination was carried out by making one setting only of $p_{\max }$ and $p_{\min }$ at one wave length $(565.0 \mathrm{~m} \mu)$ somewhat lower than that which preliminary determination indicated for the maximum, then a single determination approximately at the wave length of the maximum $(567.5 \mathrm{~m} \mu)$, and finally a single determination at a wave length $(570.0 \mathrm{~m} \mu)$ slightly above that for the maximum. After a rest

\footnotetext{
7 K. S. Gibson and E. P. T. Tyndall, The visibility of radiant energy, BS Sci. Pap. 19, 131 (1923-24) S475. Proc. Int. Comm. on Illum., 6th meeting, Geneva, 1924 (University Press, Cambridge, England) p. 67 and $232(1926)$.

$8 \mathrm{See}$, for example, D. B. Judd, Precision of color temperature measurements under various observing conditions; a new color comparator for incandescent lamps, BS J. Research 5, 1164 (1930) RP252.
} 
period, the observer repeated the series starting with the higher wave length. In this way, changes in criteria were avoided (long-time fluctuations), and practice and fatigue effects (short-time fluctuations) reduced. From this work it was concluded that the wave length at which $p_{\text {mean }}$ is a maximum is for this observer (FGB, left eye) $568.0 \pm$ $1.0 \mathrm{~m} \mu$.

\section{RESULTS}

Figure 1 shows on a logarithmic scale as a function of wave length the result of every separate determination taken by IGP by the flicker method. Figure 2 similarly shows those taken by FGB.

Table 1 gives the average values of $p_{\text {mean }}$ for each observer. These averages were obtained by plotting points representing the averages of the groups of points shown on figures 1 and 2 on a logarithmic scale together with similar points derived from data obtained with the equality-of-brightness method. Smooth curves were drawn among these points, greater weight being given to the flicker determinations. The flicker method is not open to the two criticisms of the equalityof-brightness method discussed in the previous section, and it has the further advantage of greater precision in the measurement of the smaller homogeneous brightnesses. This greater precision is particularly marked for the extremes of the spectrum (400 to $450 \mathrm{~m} \mu$, 630 to $680 \mathrm{~m} \mu$ ); in these regions it sometimes happened that the equality-of-brightness method even gave negative values for $p_{\mathrm{m} \text { in }}$ in spite of the nature of the experiment, which insures that some amount of homogeneous component greater than zero must be added. It will be understood, however, that even when increased by ten- or twentyfold these very small homogeneous brightnesses added to the sunlight component may fall below the differential limen for equality-ofbrightness settings. It may therefore be concluded that the addition to sunlight of small amounts of light from the extremes of the spectrum are detectable as chromaticity differences long before they become detectable as brightness differences.

The only regular difference observed between the flicker and equality-of-brightness methods is that for the long-wave half of the spectrum the flicker method gave generally higher results. This is to be expected from the smaller field size, and since greater interest attaches to photometric results in accord with this smaller field size, the general course of the flicker determinations was followed closely in drawing the curve. The greater weight attached to the flicker determinations was therefore of two kinds: That attached to more representative photometric observing conditions, and that to determinations of higher precision. 


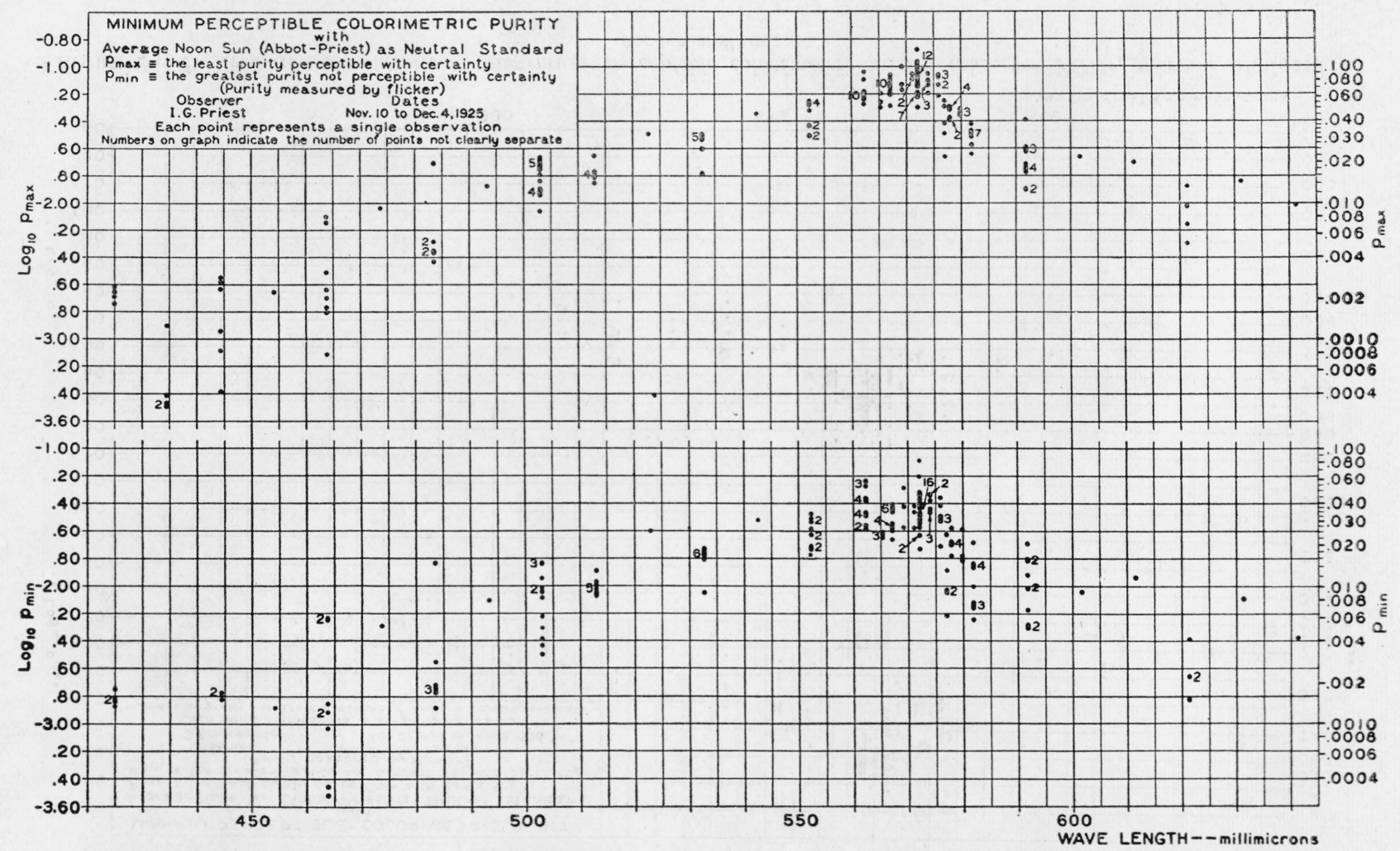

FIGURE 1.-Individual observations of minimum perceptible colorimetric purity (observer IGP), mixture analyzed by ficker method. 


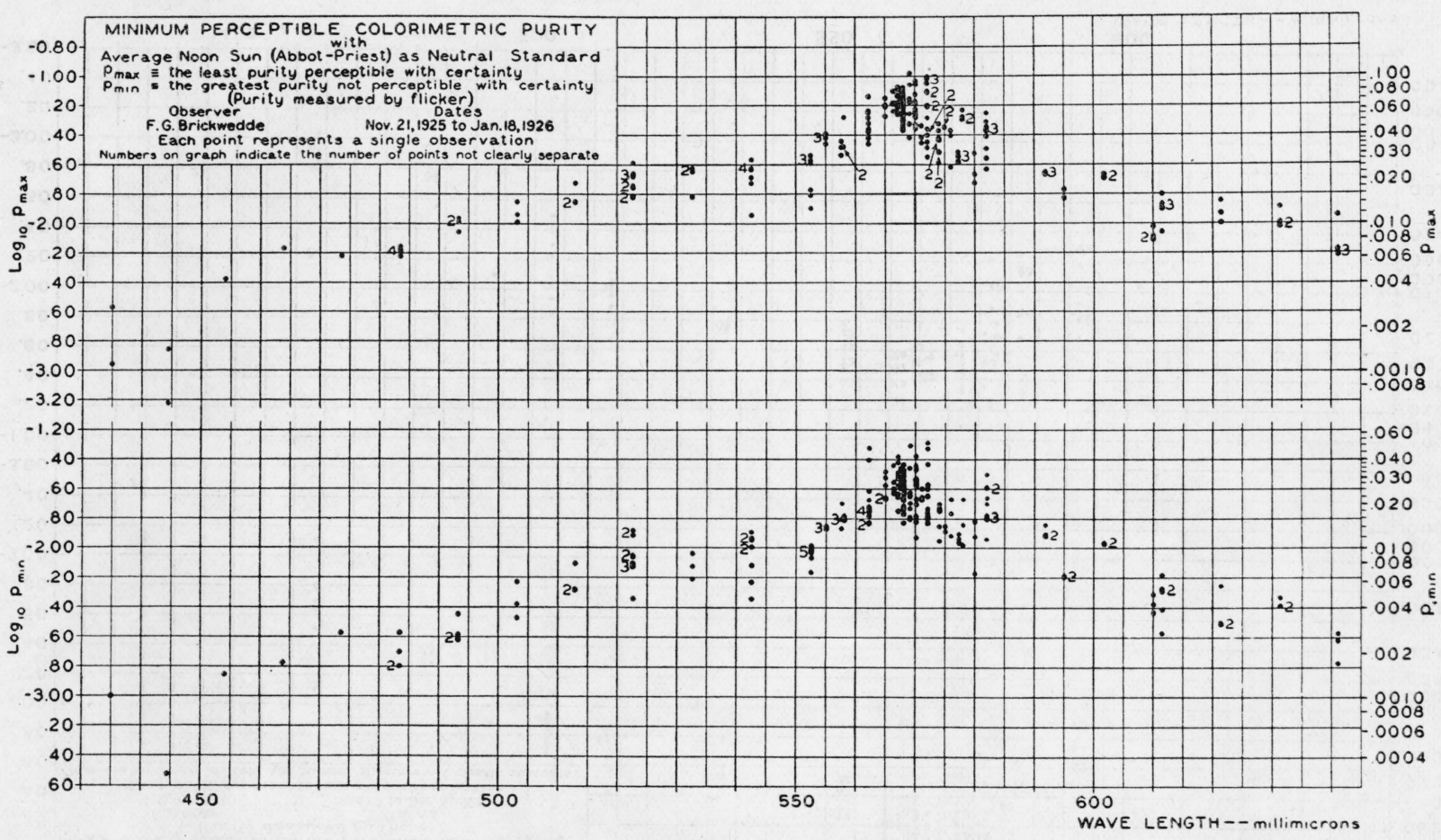

FIGURE 2.-Individual observations of minimum perceptible colorimetric purity (observer FGB), mixture analyzed by flicker method. 
TABLE 1.-Minimum perceptible colorimetric purity

\begin{tabular}{|c|c|c|c|c|c|c|c|}
\hline \multirow{2}{*}{$\begin{array}{l}\text { Wave } \\
\text { length }\end{array}$} & \multicolumn{2}{|c|}{$p_{\text {mean }}$} & \multirow{2}{*}{$\underset{p_{\text {mean }}}{\text { A verage }}$} & \multirow{2}{*}{$\begin{array}{l}\text { Wave } \\
\text { length }\end{array}$} & \multicolumn{2}{|c|}{$p_{\text {mesn }}$} & \multirow{2}{*}{$\begin{array}{c}\text { Average } \\
p_{\operatorname{mean}}\end{array}$} \\
\hline & IGP & FGB & & & IGP & FGB & \\
\hline $\begin{array}{l}m_{\mu} \\
405 \\
10 \\
20 \\
30 \\
35\end{array}$ & $\begin{array}{l}0.00105 \\
.00105 \\
.0011 \\
.00115 \\
.0012\end{array}$ & $\begin{array}{l}0.0013 \\
.0015 \\
.00195 \\
.0024\end{array}$ & $\begin{array}{r}0.00118 \\
.00128 \\
.00152 \\
.00178 \\
\end{array}$ & $\begin{array}{l}m_{\mu} \\
557.5 \\
60 \\
62.5 \\
65 \\
67.5\end{array}$ & $\begin{array}{r}0.0340 \\
.0387 \\
.0454 \\
.0516 \\
.0564\end{array}$ & $\begin{array}{r}0.0272 \\
.0322 \\
.0374 \\
.0422 \\
.0447\end{array}$ & $\begin{array}{l}0.0306 \\
.03545 \\
.0414 \\
.0469 \\
.05055\end{array}$ \\
\hline $\begin{array}{l}40 \\
45 \\
50 \\
55 \\
60\end{array}$ & $\begin{array}{l}.0013 \\
.0014 \\
.0016 \\
.0019 \\
.00235\end{array}$ & $\begin{array}{l}.00305 \\
.00375 \\
.00405 \\
.0043\end{array}$ & $\begin{array}{l}.00218 \\
.00268 \\
.00298 \\
.00332\end{array}$ & $\begin{array}{l}568 \\
70 \\
71.5 \\
72.1 \\
72.5\end{array}$ & $\begin{array}{l}.0594 \\
.0604 \\
.0603\end{array}$ & $\begin{array}{l}.0447 \\
.0432 \\
.0405 \\
.0364\end{array}$ & $\begin{array}{c}.0513 \\
.04835\end{array}$ \\
\hline $\begin{array}{l}65 \\
70 \\
75 \\
80 \\
85\end{array}$ & $\begin{array}{l}.00315 \\
.0043 \\
.00535 \\
.00635 \\
.0074\end{array}$ & $\begin{array}{l}.0044 \\
.0045 \\
.0046 \\
.0047 \\
.0050\end{array}$ & $\begin{array}{l}.00378 \\
.0044 \\
.00498 \\
.00552 \\
.0062\end{array}$ & $\begin{array}{l}73.5 \\
75 \\
76 \\
77.5 \\
78.5\end{array}$ & $\begin{array}{l}.0595 \\
.0548 \\
.0452 \\
.0340 \\
.0289\end{array}$ & $\begin{array}{r}.0306 \\
.0262 \\
.0229 \\
\end{array}$ & $\begin{array}{l}.04505 \\
.0405 \\
.02845 \\
\end{array}$ \\
\hline $\begin{array}{r}90 \\
95 \\
500 \\
05 \\
10\end{array}$ & $\begin{array}{l}.0086 \\
.00995 \\
.0115 \\
.0131 \\
.0149\end{array}$ & $\begin{array}{l}.00565 \\
.0065 \\
.00755 \\
.00875 \\
.0102\end{array}$ & $\begin{array}{l}.00712 \\
.00822 \\
.00952 \\
.01092 \\
.01255\end{array}$ & $\begin{array}{l}80 \\
82.5 \\
85 \\
90 \\
600\end{array}$ & $\begin{array}{l}.0258 \\
.0226 \\
.0206 \\
.0176 \\
.0137\end{array}$ & $\begin{array}{l}.0208 \\
.0176 \\
.0150 \\
.0114\end{array}$ & $\begin{array}{l}.0233 \\
.0191 \\
.0163 \\
.01255\end{array}$ \\
\hline $\begin{array}{l}15 \\
20 \\
25 \\
30 \\
35\end{array}$ & $\begin{array}{l}.0169 \\
.0190 \\
.0214 \\
.0238 \\
.0264\end{array}$ & $\begin{array}{l}.0118 \\
.0132 \\
.0143 \\
.0148 \\
.01495\end{array}$ & $\begin{array}{l}.01435 \\
.0161 \\
.01785 \\
.0193 \\
.02068\end{array}$ & $\begin{array}{l}10 \\
20 \\
30 \\
40 \\
50\end{array}$ & $\begin{array}{l}.0111 \\
.0090 \\
.00745 \\
.0062 \\
.00545\end{array}$ & $\begin{array}{l}.0087 \\
.0073 \\
.00685 \\
.00655 \\
.00635\end{array}$ & $\begin{array}{l}.0099 \\
.00815 \\
.00715 \\
.00638 \\
.0059\end{array}$ \\
\hline $\begin{array}{l}40 \\
45 \\
50 \\
52.5 \\
55\end{array}$ & $\begin{array}{l}.0286 \\
.0300 \\
.0308 \\
.0312 \\
.0320\end{array}$ & $\begin{array}{l}.01505 \\
.0152 \\
.0166 \\
.0189 \\
.0225\end{array}$ & $\begin{array}{l}.02182 \\
.0226 \\
.0237 \\
.02505 \\
.02725\end{array}$ & $\begin{array}{l}60 \\
70 \\
80\end{array}$ & $\begin{array}{l}.0051 \\
.0049 \\
.00485\end{array}$ & $\begin{array}{l}.0062 \\
.006125 \\
.00605\end{array}$ & $\begin{array}{l}.00565 \\
.00551 \\
.00545\end{array}$ \\
\hline
\end{tabular}

The values of the first two columns in table 1 were computed from values of $p_{\max }$ and $p_{\min }$ read from these adopted curves. The values in the last column of table 1 are the arithmetical means of the values in the first two columns.

Figure 3 shows (solid curve) a plot on a logarithmic scale of a smooth curve drawn through the values given fin the last column of table 1. It also shows curves of $p_{\max }$ (dotted curve, arithmetical mean of $p_{\max }$ for IGP and $p_{\max }$ for FGB) and $p_{\min }$ (dashed curve, arithmetical mean of $p_{\min }$ for IGP and $p_{\min }$ for FGB).

\section{DISCUSSION}

\section{COMPARISON WITH OTHER WORK}

When these data were obtained there was only one investigation with which to compare them; this was the pioneer work of Jones and Lowry ${ }^{9}$ on saturation scales extending from zero purity to the spectrum (unit purity) for eight different wave lengths. Although subsequent repetition of this work has in the main corroborated it, the variation with dominant wave length of the first saturation step from zero purity found by Jones and Lowry incidental to their main purpose is much less than that reported here. For example, Jones and Lowry give 0.035 as the size of the first purity step for $575 \mathrm{~m} \mu$ and 0.025 for

' L. A. Jones and E. M. Lowry, Retinal sensibility to saturation differences, J. Opt. Soc. Am. and Rev. Sci: Instr. 13, 25 (1926). 
$440 \mathrm{~m} \mu$; this is a variation by a factor of about 1.4, while from table 1 the corresponding variation is by a factor of about 18 .

Since 1926, however, $p_{\max }$ has been redetermined by no less than three independent investigations, those by Purdy. ${ }^{10}$ by Martin, Warburton, and Morgan, ${ }^{11}$ and by Wright and Pitt, ${ }^{12}$ Purdy investigated the change in $p_{\max }$ with field brightness, and therefore extended the scope of his work over that of the present results in an important particular; but he used stimuli of relatively few wave lengths (8) over

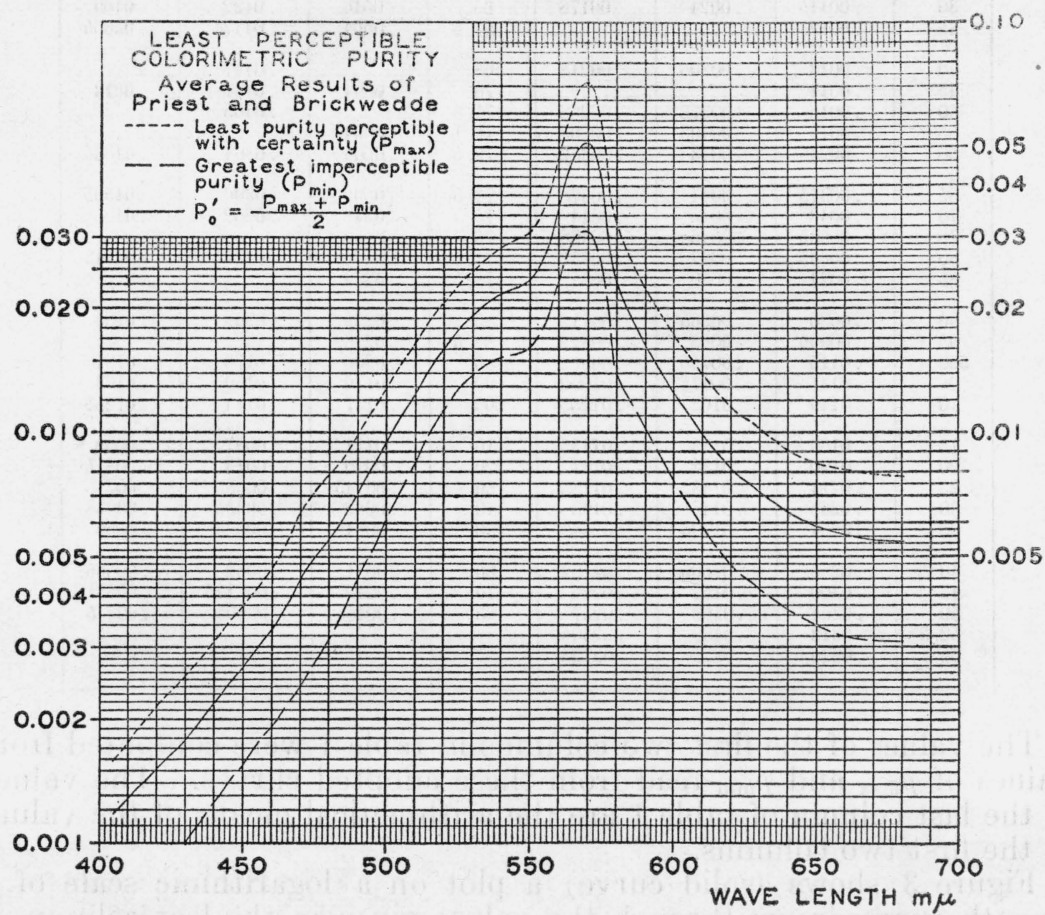

FIGURE 3.-Minimum perceptible colorimetric purity, average results of Priest and Brickwedde.

the range 400 to $660 \mathrm{~m} \mu$. Martin, Warburton, and Morgan supply data for three observers, both for light adaptation and dark adaptation; their investigation refers to 21 wave lengths distributed over the range 440 to $680 \mathrm{~m} \mu$. Wright and Pitt obtained data at 19 wave lengths distributed uniformly over the range 470 to $650 \mathrm{~m} \mu$. In each of these investigations the results completely corroborate within experimental error those previously obtained by Priest and Brickwedde, with exceptions arising only from the fact that the PriestBrickwedde results cover a greater wave-length range more thoroughly than any other investigation.

\footnotetext{
${ }_{10} \mathrm{D}$. McL. Purdy, On the saturations and chromatic thresholds of the spectral colours, Brit. J. Psychol. (Gen. Sec.) 21 (pt. 3), 283 (1931).

11 L. C. Martin. F. L Warburton, and W. J. Morgan, Determination of the Sensitiveness of the Eye to Differences in the Saturation of Colours, Medical Research Council, Reports of the Committee upon the Physiology of Vision, XIII, Special Report Series, No. 188 (London, 1933).

19 W. D. Wright and F. H. G. Pitt, The saturation-discrimination of two trichromats, Proc. Phys. Soc. (London) 49, 329 (1937).
} 
There can therefore be no doubt remaining as to the essential correctness of the data presented here completely for the first time. ${ }^{13}$

\section{INTERPRETATION}

Through the courtesy of Mr. Priest these data were, in advance of publication, placed at the disposal of Dr. Selig Hecht and the writer. By an extension of the Young three-component theory of vision Hecht has shown that these data are consistent with sensibility to wave-length change in the spectrum and roughly consistent with the mixture data of the OSA "excitation" curves, used for many years as a definition of normal vision. ${ }^{14}$ These data have formed an important basis for Hecht's further theoretical papers, in which he has shown that they may be completely harmonized with the OSA curves. ${ }^{15}$ Judd has shown by an empiric relation that these data are consistent with many other chromaticity-sensibility functions and are approximately consistent both with the mixture data and coordinate system of the OSA "excitation" curves, ${ }^{16}$ and he has also shown by a special transformation of coordinates that these data are in precise agreement with the mixture data of the standard observer adopted in 1931 by the International Commission on Illumination. ${ }^{17}$

From their appearance in summarized form in these publications, the Priest-Brickwedde data have continued to spread ${ }^{18}$ and in this way have already exerted a considerable influence on modern developments in visual theory.

It is probably worth noting that Priest for some time held the view that $p_{\text {mean }}$ should duplicate very closely the luminosity function. This caused him to remark " "Least perceptible purity is largely dependent upon visibility; the relative amounts of energy required to introduce a hue difference show comparatively small variation with wave length," and to view with suspicion the presence (see fig. 3) of the marked maximum quite definitely removed $(570 \mathrm{~m} \mu)$ from the wave length of maximum spectral luminosity $(555 \mathrm{~m} \mu)$. He was inclined to the belief that if a truly achromatic stimulus were to be substituted for the rather greenish-yellow artificial sunlight then this pronounced maximum at $570 \mathrm{~m} \mu$ would no longer be found. This belief led him to remark, "Further extensive investigation of least perceptible purity should be prefaced by a definite adoption of a neutral standard."

The present view of this maximum at $570 \mathrm{~m} \mu$ is that it indicates sunlight to be more confusible in chromaticity with $570 \mathrm{~m} \mu$ than with any

13 Martin, Warburton, and Morgan (see footnote 11, p. 680) give a discussion of possible sources of unreliability of the Jones-Lowry data. See, also, D. B. Judd, Chromaticity sensibility to stimulus differences, J. Opt. Soc. Am. 22, 95 (1932).

1 Selig Hecht, The development of Thomas Young's theory of color vision, J. Opt. Soc. Am. 20, 231 (1930). The tentative theoretical curves in this paper do not completely harmonize mixture data for the normal eye with the Priest-Brickwedde data; consult D. B. Judd, The mixture data embodied in the tentative curves of Hecht's theory of vision, J. Opt. Soc. Am. 20, 647 (1930); this deviation has been taken care of in Hecht's subse-

quent formulation of Young's idea. tative Formulation of Colour-Vision, Report of a Joint Discussion of Vision, The Physical and Optical Societies, June 1932; The Retinal Processes Concerned with Visual Acuity and Color Vision, Bulletin No. 4, Howe Laboratory of Ophthalmology, Harvard Medical School (Harvard University Press, Cambridge, Mass., August 1931.)

${ }_{16}$ D. B. Judd, Chromaticity sensibility to stimulus differences, J. Opt. Soc. Am., 22, 72 (1932)

$17 \mathrm{D}$. B. Judd, A Maxwell triangle yielding uniform chromaticity scales, J. Research NBS 14, 41 (1935); RP756; J. Opt. Soc. Am. 25, 24 (1935).

is See, for example, J. F. Schouten, Grundlagen einer quantitativen Vierfarbentheorie. I, Proc. Konink Akad. Wetenschappen Amsterdam 38, No. 6 (1935). Schouten, like Hecht, has shown an approximate correspondence between mixture data for the normal eye and the Priest-Brickwedde data by resort to a certain form of visual theory.

19 I. G. Priest and F. G. Brickwedde, The minimum perceptible colorimetric purity as a function of dominant wave length with sunlight as neutral standard, J. Opt. Soc. Am. and Rev. Sci. Instr. 13, 306 (1926). 
other part of the spectrum. On the basis of this conclusion, a new coordinate system was derived, ${ }^{20}$ which has not only been successful in coordinating chromaticity sensibility data of various sorts but has also proved to be useful in practical specification of color tolerances and in the estimation for practical purposes of nearest chromaticity from a chromaticity series. ${ }^{21}$ The success of these colorimetric procedures can largely be traced to the Priest-Brickwedde data.

\section{Washington, January 2, 1938.}

${ }^{20}$ D. B. Judd, A Maxwell triangle yielding uniform chromaticity scales, J. Research NBS 14, 41 (1935) RP756; J. Opt. Soc. Am. 25, 24 (1935).

${ }_{21}$ D. B. Judd, $A$ method for determining whiteness of paper, Paper Trade J., Tech. Sec. 100, 266 (1935); 103, 154 (1936); Tech. Assn. Papers, series 18, 392 (1935); series 19, 359 (1936).

H. J. McNicholas, Color and spectral transmittance of vegetable oils, J. Research NBS 15, 99 (1935) RP815; Oil and Soap 12, 167 (1935).

D. B. Judd, Estimation of chromaticity differences and nearest color temperature on the standard 1981 ICI colorimetric coordinate system, J. Research NBS 17, 771 (1936) RP944; J. Opt. Soc. Am. 26, 421 (1936).

H. J. McNicholas, Selection of colors for signal lights, J. Research NBS 17, 955 (1936) RP956.

D. B. Judd, Surface color, J. Opt. Soc. Am. 25, 44 (1935).

F. C. Breckenridge and W. R. Schaub, Rectangular uniform-chromaticity-scale coordinates, J. Opt. Soc. Am. 27, 226 (1937).

D. L. MacAdam, Projective transformations of ICI color specifications, J. Opt. Soc. Am. 27, 294 (1937). 